\title{
Characterization of P92 Steel Weldments in As-Welded and PWHT Conditions
}

\author{
Room-temperature tensile tests and microhardness \\ measurements led to improving the ductility of the weld joints
}

BY N. SAINI, C. PANDEY, M. M. MAHAPATRA, AND R. S. MULIK

\begin{abstract}
P92 steels have been developed as a candidate material for power plant components that operate in a temperature range of $620^{\circ}-650^{\circ} \mathrm{C}$. A heterogeneous microstructure formation across the P92 weldments makes the weldability of P92 steel a serious issue. The other problem that arises in P92 steel weldments is the formation of $\delta$-ferrite due to the presence of a higher weight percentage of ferrite stabilizers such as $\mathrm{V}$ and $\mathrm{Nb}$, as well as $\mathrm{W}$ and $\mathrm{Mo}$. In the present work, the shielded metal arc welding (SMAW) process was utilized to prepare the P92 steel weld joints. After welding, postweld heat treatment (PWHT) was performed at $760^{\circ} \mathrm{C}$ for $2 \mathrm{~h}$. To characterize the weld joints, room-temperature tensile tests and microhardness measurements were performed in the as-welded and PWHT conditions. The subsequent PWHT resulted in a decrease in the hardness gradient across the weldments. The PWHT resulted in enhancing the ductility of the weld joints.
\end{abstract}

\section{KEYWORDS}

- P92 Steel • Postweld Heat Treatment (PWHT)

- Hardness • $\delta$-Ferrite • Tensile Properties

\section{Introduction}

Creep strength enhanced ferritic (CSEF) steels are one of the important candidate materials in power plants due to excellent physical, thermal, and mechanical properties (Refs. 1, 2). The CSEF P92 steel was developed in Japan by Nippon steel (Ref. 3). P92 steel offers enhanced creep strength, which results from the combination of precipitation and solid-solution hardening (Refs. 4, 5). The P92 steel microstructure consists of a tempered martensitic structure that derives its stability from finely dispersed V- and $\mathrm{Nb}$-rich $\mathrm{MX}(\mathrm{X}: \mathrm{C}, \mathrm{N})$ type precipitates inside the matrix region and $\mathrm{Fe}-, \mathrm{Cr}$-, and Mo-rich coarse $\mathrm{M}_{23} \mathrm{C}_{6}$ precipitates along the prior austenite grain boundaries (PAGBs) (Refs. 6, 7). The optimum combination of toughness and creep strength is derived from the stable tempered martensitic microstructure (Refs. 8, 9). These fine precipitates helped to enhance the long-term creep rupture life of P92 steel by pinning the movement of subgrain boundaries (Ref. 10).

In steam generator components, most of the failures occurred in the welded joints, which created the need to study welded joints (Ref. 11). During welding, the temper martensitic microstructure was adversely altered by the formation of fresh martensite in the weldments (weld fusion zone + heat-affected zones) (Ref. 12). During the welding process, P92 steel showed a great tendency for $\delta$-ferrite formation due to the presence of ferrite stabilizers like $\mathrm{V}, \mathrm{Nb}, \mathrm{W}, \mathrm{Mo}$, and $\mathrm{Cr}$. The presence of $\delta$-ferrite patches in P92 steel welds was also observed; a negative effect on mechanical properties due to notch sensitivity of the $\delta$-ferrite (Refs. 13,14 ). It is possible to control the formation of retained austenite and $\delta$-ferrite by optimizing the base and filler metal composition (Ref. 15). The high number of ferrite-forming elements resulted in excessive formation of $\delta$-ferrite (Ref. 16). Postweld heat treatment (PWHT) was performed to overcome the hardness gradient and temper the brittle martensite (Ref. 17). The PWHT resulted in a great reduction in hardness, improving the ductility and toughness of the weldments (Ref. 18).

\section{Experimental Details}

As per the manufacturer, as-received P92 steel was subjected to normalized and tempered conditions. Normalizing was carried out at $1040^{\circ} \mathrm{C}$ for $60 \mathrm{~min}$ to develop the lath martensitic microstructure with high dislocation density, while tempering was performed at $760^{\circ} \mathrm{C}$ for $2 \mathrm{~h}$ for the evo- 


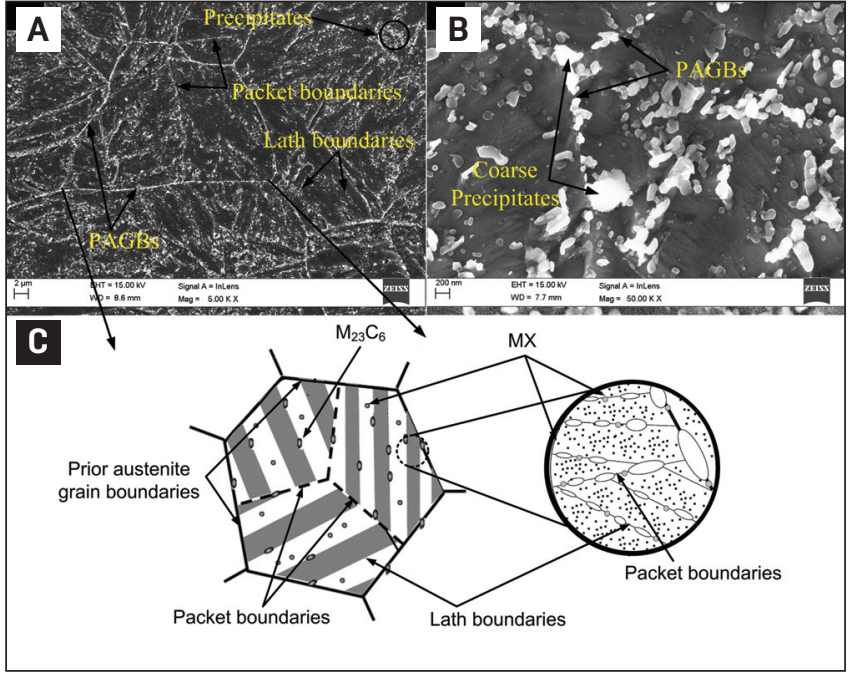

Fig. 1 - Microstructure of the following: $A$ and B - As-received P92 steel; and C - schematic of a prior austenite grain.

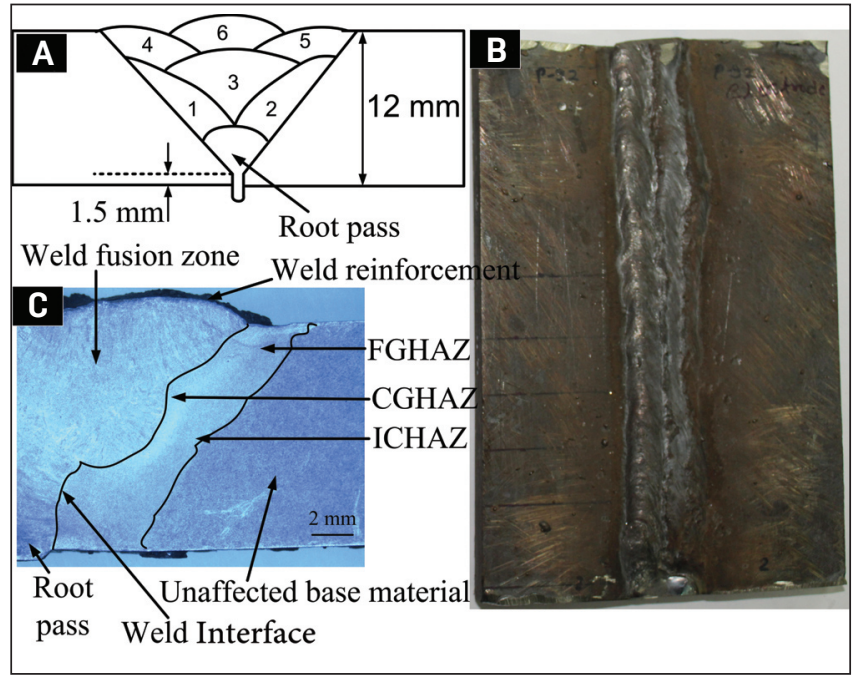

Fig. 2 - A - Schematic of the welding passes; B - complete weld joint; and $\mathrm{C}$ - cross section of the weld joint.

Table 1-Chemical Compositions of As-Received Materials, Wt-\%

\begin{tabular}{ccccccccccccccccc} 
Element & $\mathrm{C}$ & $\mathrm{Mn}$ & $\mathrm{P}$ & $\mathrm{S}$ & $\mathrm{Si}$ & $\mathrm{Cr}$ & $\mathrm{Mo}$ & $\mathrm{V}$ & $\mathrm{Al}$ & $\mathrm{Nb}$ & $\mathrm{W}$ & $\mathrm{Cu}$ & $\mathrm{Ni}$ & $\mathrm{N}$ & $\mathrm{Fe}$ \\
\hline Base & 0.10 & 0.58 & 0.007 & 0.003 & 0.48 & 9.09 & 0.42 & 0.24 & 0.02 & 0.07 & 1.86 & 0.03 & 0.30 & 0.02 & Rest & \\
Filler & 0.11 & 0.60 & 0.008 & 0.005 & 0.19 & 8.90 & 0.45 & 0.22 & - & 0.06 & 1.82 & 0.04 & 0.35 & 0.06 & Rest \\
\hline
\end{tabular}

lution of precipitates that provide the microstructure stability. The chemical compositions of as-received plates and filler rod are depicted in Table 1.

The plates sized $150 \times 60 \times 12 \mathrm{~mm}$ were prepared from as-received plates. A V-groove was produced for making weld joints. The root height and groove angle were taken as $1.5 \mathrm{~mm}$ and $37.5 \mathrm{deg}$, respectively. Shielded metal arc welding (SMAW) was utilized to produce P92 steel weld joints. The P92 steel filler rod (flux coated, $4 \mathrm{~mm}$ diameter) was used with a welding current of 140 A and arc voltage in the range of 23-26 V. Before welding, preheating was performed at a temperature of $300^{\circ} \mathrm{C}$ using flame heating. Before PWHT, the postweld heating was also performed at $250^{\circ} \mathrm{C}$ for $40 \mathrm{~min}$ to remove the diffusible hydrogen content (Ref. 19).

After the postweld heating, postweld heat treatment (PWHT) was performed at $760^{\circ} \mathrm{C}$ for $2 \mathrm{~h}$. To characterize the sample, shaping, grinding, paper polishing, and cloth polishing were performed. After polishing, samples were etched in Vilella's reagent. Samples were characterized using a field-emission scanning electron microscope (FESEM), microhardness tester (Omnitech S. Auto), and vertical tensile testing machine (Instron:5982) techniques. According to ASTM E8/E8M, the transverse flat subsize tensile specimens were prepared with a gauge width of $6 \mathrm{~mm}$ and gauge length of $25 \mathrm{~mm}$ (Ref. 20). Room-temperature tensile tests were performed at a constant cross-head speed of $1 \mathrm{~mm} / \mathrm{min}$. In addition, a Vicker's microhardness tester was used for the hardness measurement at a 500-g load and dwell time of $10 \mathrm{~s}$.

\section{Results and Discussion}

\section{As-Received Material}

The micrographs of P92 steel in low and high magnifications are shown in Fig. $1 \mathrm{~A}$ and $\mathrm{B}$, respectively. The low magnification micrograph consists of PAGBs with packets, laths, packet boundaries, and blocks of laths, as shown in Fig. 1A. The distribution and morphology of coarse $\mathrm{M}_{23} \mathrm{C}_{6}$-type precipitates and fine MX precipitates at lath boundaries and PAGBs were clearly seen at higher magnification, as shown in Fig. 1B. Evolution of precipitates along PAGB, lath blocks, packet boundaries, and inside intra lath region is shown in schematic diagram of Fig. 1C. It defines the lath boundaries, packet boundaries, packet, columnar laths, PAGBs, coarse $\mathrm{M}_{23} \mathrm{C}_{6}$ precipitates, and fine MX precipitates. The ultimate tensile strength (UTS), \% elongation, microhardness, and impact toughness of as-received P92 steel were measured as $678 \pm 10$ $\mathrm{MPa}, 23 \pm 2 \%, 227 \pm 4 \mathrm{HV}$, and $198 \pm 8 \mathrm{~J}$, respectively.

\section{Characterization of Weldments}

Figure 2A shows the weld joint after welding completion. The optimized base material microstructure was changed completely by an applied welding cycle. Based on temperature experience, the P92 weldments are divided into the weld fusion zone and narrow heat-affected zones (HAZs). Narrow HAZs show the continuous microstructure change due to the varying temperature range, and it is divided into coarse grain (CG), fine grain (FG), intercritical (IC), and 


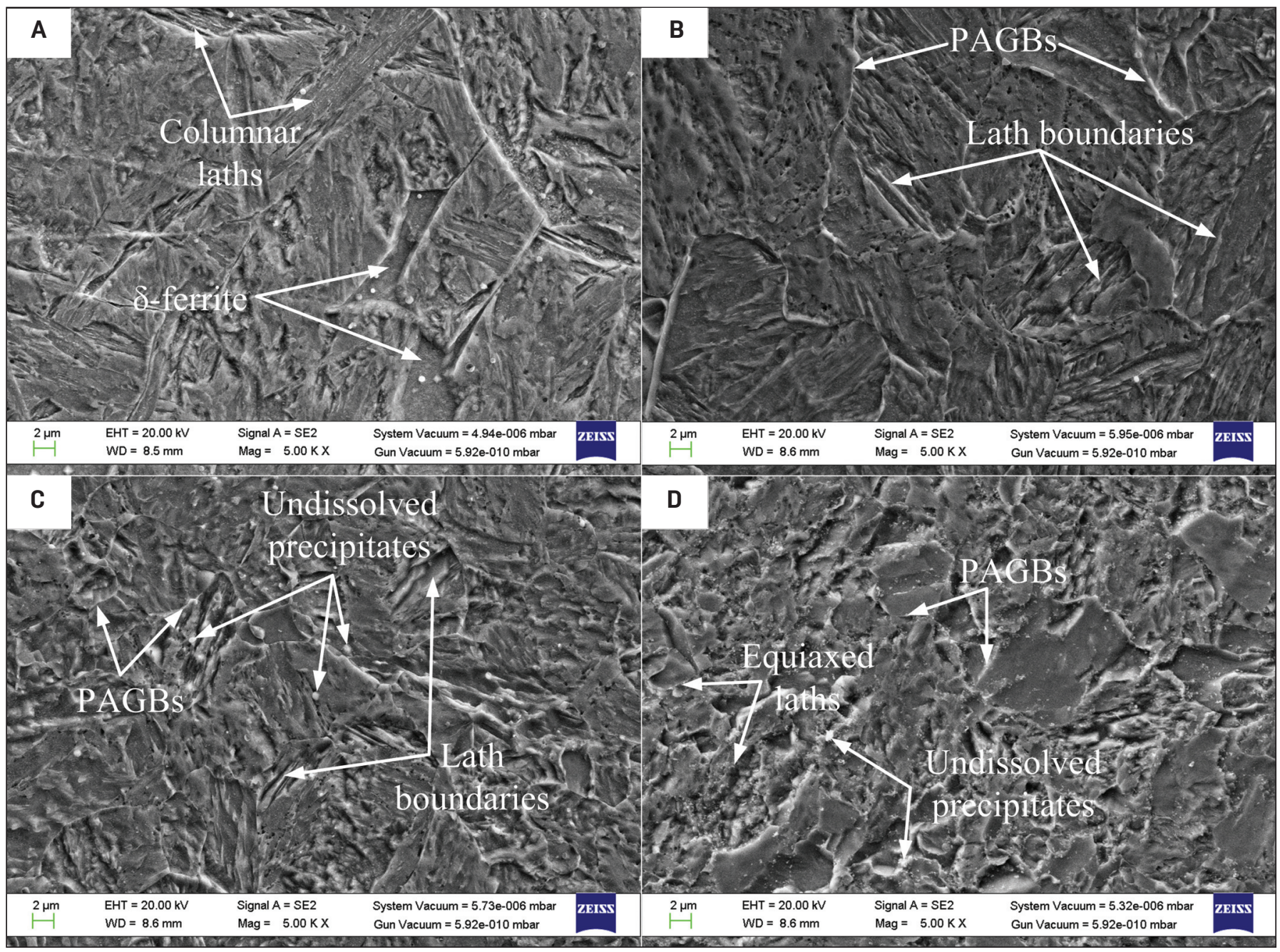

Fig. 3 - Secondary electron micrographs in the as-welded condition: A - Weld fusion zone; B - CGHAZ; C - FGHAZ; and D - ICHAZ.

overtempered base material. The P92 steel weld showing the weld fusion zone, various zones formed in the HAZ, and features of the weld are shown in Fig. 2B.

A typical untempered columnar lath microstructure of the weld fusion zone is shown in Fig. 3A. The microstructure also shows the $\delta$-ferrite. In P92 steel, a high weight percentage of ferrite stabilizer elements like W and Mo promote $\delta$-ferrite formation. In P92 steel weldments, the presence of $\delta$-ferrite was undesired with respect to poor weld toughness. The zone adjacent to the weld fusion zone experienced temperatures much above the transformation temperature $\left(\mathrm{Ac}_{3}\right)$ and denoted as coarse grain heat-affected zone (CGHAZ). The dissolution of precipitates occurred at such a high temperature, which resulted in a higher amount of carbon $(\mathrm{C})$ and nitrogen $(\mathrm{N})$ in the solid-solution matrix. The pinning force by the precipitates was also reduced due to dissolution of precipitates, which resulted in formation of coarse grains of austenite. Hence, in the as-welded condition, coarse grain lath martensitic structure was observed in the CGHAZ, as shown in Fig. 3B. The fine grain heat-affected zone (FGHAZ) experienced a temperature just above $\mathrm{Ac}_{3}$.

Fewer coarse $\mathrm{M}_{23} \mathrm{C}_{6}$ and fine $\mathrm{MX}$ precipitates remain undissolved because the temperature was not capable of dissolving the precipitates completely, as shown in Fig. 3C.
The size of coarse $\mathrm{M}_{23} \mathrm{C}_{6}$ was observed to be varied from 574 to $723 \mathrm{~nm}$ with an average precipitate size of $638 \pm 62 \mathrm{~nm}$. The fine MX precipitates are difficult to resolve using the SEM micrographs. The growth of austenite grain impeded by these undissolved precipitates resulted in the fine prior austenite grains (PAGs) structure. Some $\delta$-ferrite patches were also observed in the FGHAZ. In P92 steel weldments, the mild intercritical heat-affected zone (ICHAZ) was found to be an interesting region, which had a mixed combination of new prior austenite grains and remaining coarse tempered grains, with some undissolved precipitates and coarse tempered precipitates, as shown in Fig. 3D.

In the PWHT condition, evolution of dissolved precipitates occurs. After PWHT, the microstructural evolution and distribution of carbide precipitates in the weldments are shown in Fig. 4A-D. The PWHT of P92 weldments lead to the evolution of precipitates and coarsening of existing precipitates. Evolution of precipitates and coarsening of existing precipitates in every zone of $\mathrm{P} 92$ steel weldments is shown in Fig. 4A-D. The PWHT results in overtempering of the base metal. The overtempering does not contribute so much in microstructural change. Overtempering does not allow the phase change, but it leads to negligible coarsening of $\mathrm{M}_{23} \mathrm{C}_{6}$-type carbide precipitates. 


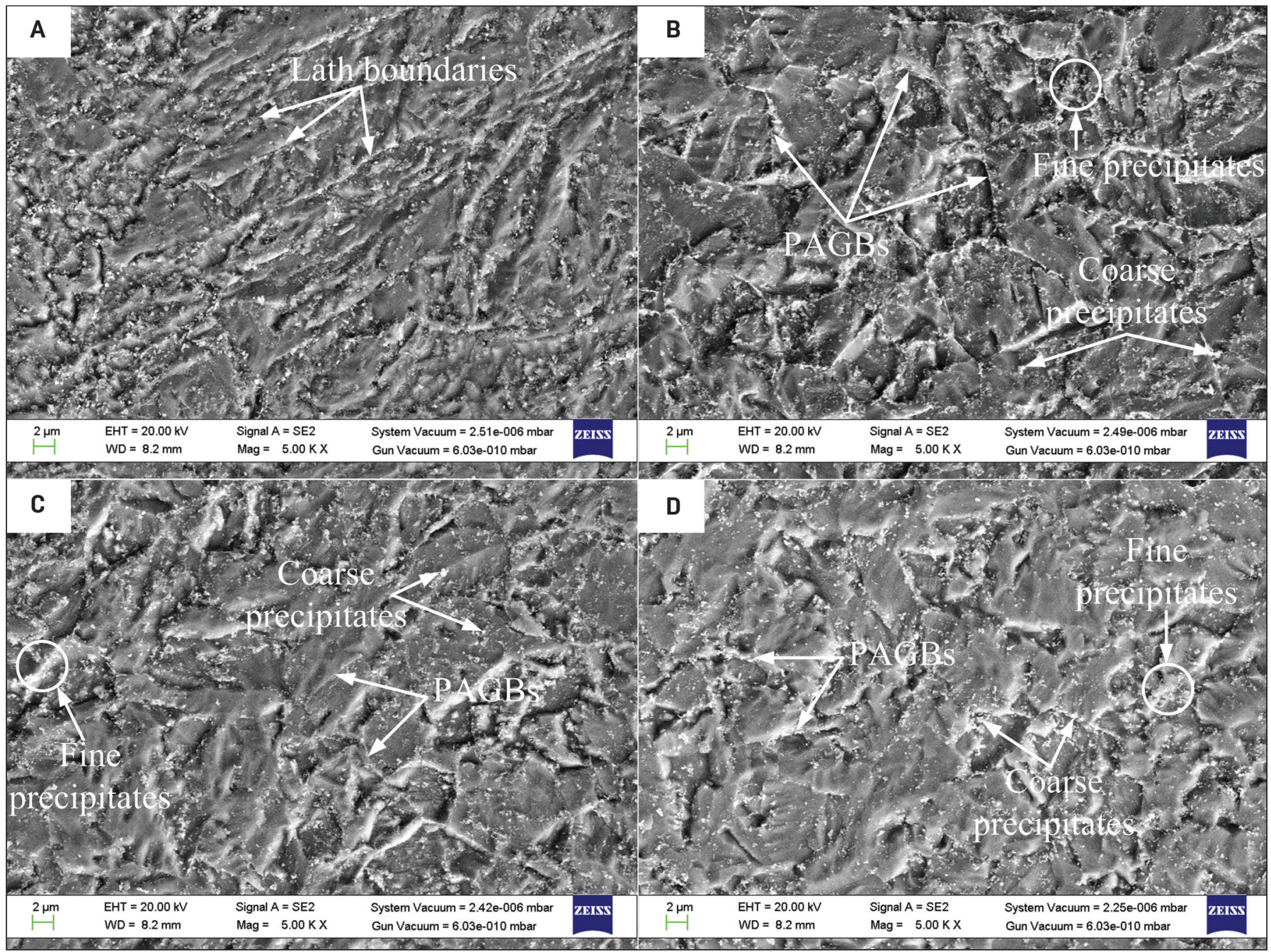

Fig. 4 - Secondary electron micrographs after PWHT: A - Weld fusion zone; B - CGHAZ; C - FGHAZ; and D - ICHAZ.

A schematic of microstructure and precipitates evolution in the FGHAZ for different heating conditions is presented in Fig. 5. In the as-received condition, packet boundaries, martensite block, and $\mathrm{M}_{23} \mathrm{C}_{6}$ precipitates along PAGBs were observed. The MX precipitates were also noticed inside the martensite lath blocks and at martensite block boundaries. In the FGHAZ, the small-sized $\mathrm{M}_{23} \mathrm{C}_{6}$ precipitates and subgrains were dissolved during welding. During the PWHT of P92 steel weldments, the $\mathrm{M}_{23} \mathrm{C}_{6}$-type carbides would reprecipitate on block boundaries and PAGBs. These $\mathrm{M}_{23} \mathrm{C}_{6}$ precipitates prevent the recrystallization by pinning the boundaries. The supersaturated carbon $(C)$ will favor the growth of undissolved $\mathrm{M}_{23} \mathrm{C}_{6}$ instead of the nucleation of new $\mathrm{M}_{23} \mathrm{C}_{6}$ precipitates. For the same reason, the number of newly developed MX precipitates will be less. This subtle reduction in MX precipitates results in poor mechanical properties.

After PWHT, the higher magnification secondary electron micrograph of FGHAZ shows the distribution of coarse globular and cylindrical shaped $\mathrm{M}_{23} \mathrm{C}_{6}$-type precipitates at boundaries and fine spherical MX-type precipitates inside the intra-lath region, as shown in Fig. 6A. Figure 6B shows the line mapping results of various elements present in the FGHAZ of P92 steel weldment after PWHT. At the precipi-

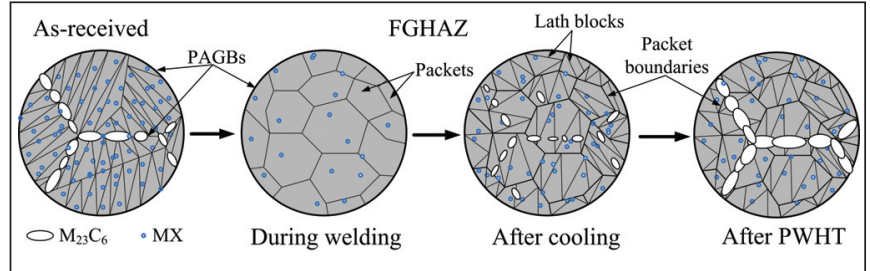

Fig. 5 - Schematic showing FGHAZ microstructural evolution after PWHT.

tates (white particles in the FGHAZ), the percentage of $\mathrm{Cr}$, $\mathrm{W}$, and Mo was found to be increased and the percentage of Fe was decreased simultaneously, which confirmed the higher weight percentage of $\mathrm{Cr}$, Mo, and $\mathrm{W}$ in $\mathrm{M}_{23} \mathrm{C}_{6}$-type carbide precipitates. The EDS analysis of coarse particles present at the PAGBs also confirms the higher weight percentage of $\mathrm{Cr}$, $\mathrm{Mo}, \mathrm{W}$, and $\mathrm{Fe}$ in $\mathrm{M}_{23} \mathrm{C}_{6}$, as shown in Fig. 6C.

\section{Room-Temperature Tensile Test}

The mechanical properties of the weldments were affected by the phase transformations taking place within 


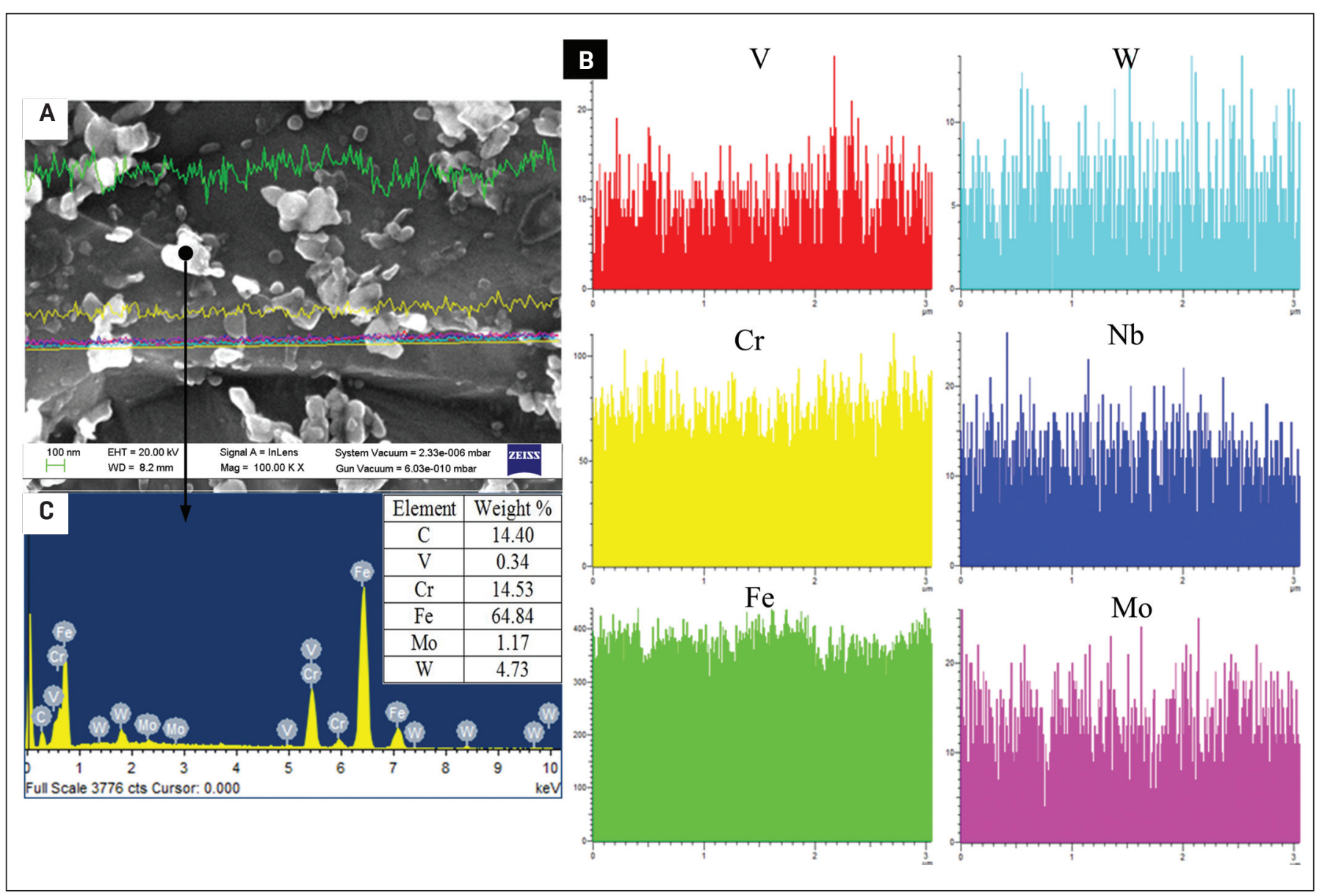

Fig. 6 - A - FGHAZ after PWHT; B - line mapping results showing variation of elements; and C - EDS of coarse precipitate present on the PAGB.

the weldments during the weld thermal cycle and PWHT. The engineering stress-strain curve for the welded specimens is shown Fig. 7. In the as-welded condition, the fracture of the tensile specimen was noticed in the soft FGHAZ region. In the as-welded condition, the ultimate tensile strength (UTS) and \% elongation were measured to be 674 $\pm 18 \mathrm{MPa}$ and $12.5 \pm 3.5 \%$, respectively. The ductility of weldments was measured to be lowest in the as-welded condition due to the high volume fraction of untempered lath martensite. After PWHT, the fracture location was shifted from FGHAZ to the overtempered base zone. After PWHT, the UTS and \% elongation were observed to be increased as compared to the as-welded condition. In the PWHT condition, the UTS and \% elongation were measured to be $785 \pm 25 \mathrm{MPa}$ and $21 \pm 4 \%$, respectively. The UTS was observed for the FGHAZ and overtempered base metal. Fracture from the FGHAZ and overtempered zone shows the higher strength of the weld fusion zone.

\section{Hardness}

The variation of microhardness in the weldments is governed by the precipitation hardening and solid-solution strengthening. Variations of microhardness across the weldments for different conditions are shown in Fig. 8.

In the weld fusion zone, the microhardness was meas- ured to be $453 \pm 24 \mathrm{HV}$ in the as-welded state. The weld fusion zone undergoes the multipass welding effect, which resulted in a great variation in hardness due to autotempering of the previous pass by subsequent pass. In the as-welded condition, a higher hardness in the weld fusion zone is attributed to a presence of higher weight percentage of $C$ and $\mathrm{N}$ in the solution matrix. As it moves away from the weld fusion zone, a gradual decrease in hardness was observed. The CGHAZ and FGHAZ hardness were measured to be $417 \mathrm{HV}$ and $403 \pm 12 \mathrm{HV}$, respectively. In the CGHAZ, a higher peak temperature results in the dissolution of precipitates that leads to $C$ and $N$ percentage in the solid-solution matrix. That results in a higher hardness in the CGHAZ among all HAZs. In the FGHAZ, partial dissolution of precipitates results in less $C$ and $\mathrm{N}$ in solid-solution matrix that leads to poor hardness of the FGHAZ as compared to the CGHAZ. After the FGHAZ, a sudden drop was observed in the hardness at the HAZ base boundary.

In the as-welded condition, the ICHAZ was identified as a soft zone, and hardness was measured to be $214 \mathrm{HV}$. The lowest hardness of the ICHAZ is attributed to the presence of coarse undissolved $\mathrm{M}_{23} \mathrm{C}_{6}$ precipitates and overtempering of martensite. The PWHT results in a considerable reduction in hardness throughout the weldments. After PWHT, the weld fusion zone hardness was measured to be $224 \pm 6 \mathrm{HV}$. The PWHT resulted in a decrease in solid-solution harden- 


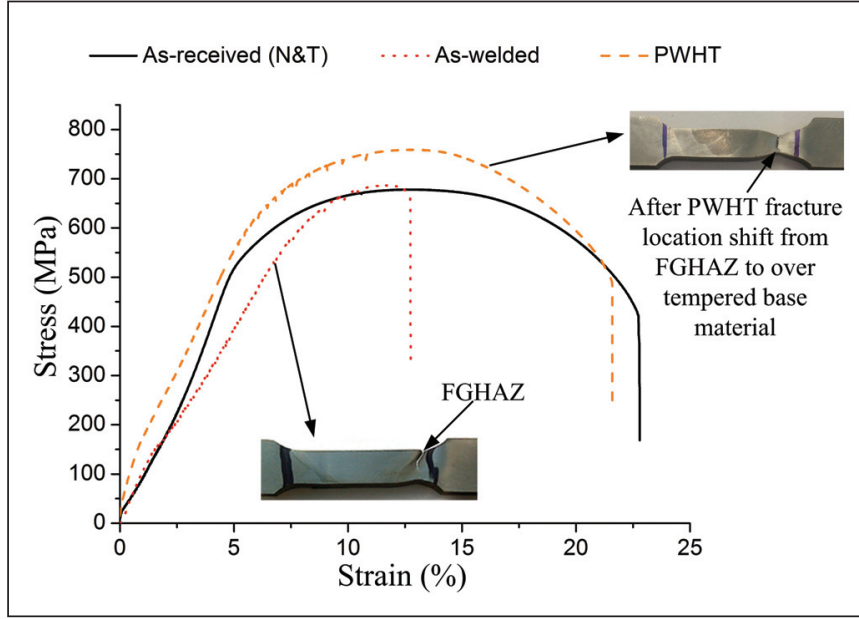

Fig. 7 - Engineering stress-strain curve for various tensile tested specimens.

ing, but at the same time, the evolution of precipitates leads to precipitation hardening. In the PWHT condition, a reduction in solid-solution hardening was observed to be dominated over the increase in precipitation hardening that resulted in a decrease in the hardness of the weldments. The average hardness of CGHAZ and FGHAZ was measured to be 219 and $205 \pm 10 \mathrm{HV}$, respectively. However, the soft ICHAZ zone still observed in the welded joints leads to poor creep strength of the P92 steel weldments.

\section{Conclusions}

The following conclusions can be made:

- The microstructures of P92 steel weldments were characterized by the untempered lath martensite, lath packets, lath boundaries, and $\delta$-ferrite.

- After PWHT, the strength and ductility were increased. In the PWHT condition, it was observed that the fracture location was shifted to overtempered base metal from the FGHAZ after the room-temperature tensile test.

- The microhardness of subzones of the P92 weldments showed the great heterogeneity in the microstructure. Maximum and minimum hardness were measured to be $453 \pm 24$, and $214 \mathrm{HV}$ for weld fusion zone and ICHAZ, respectively. After PWHT, a considerable softening was noticed in each zone of the P92 steel weldments.

\section{References}

1. Coussement, C., Dhooge, A., de Witte, M., Dobbelaere, R., and van der Donckt, E. 1991. High temperature properties of improved 9\% Cr steel weldments. Int. J. Press. Vessel. Pip. 45: 163178. DOI: doi.org/10.1016/0308-0161(91)90090-O.

2. Wang, S. S., Peng, D. L., Chang, L., and Hui, X. D. 2013. Enhanced mechanical properties induced by refined heat treatment for $9 \mathrm{Cr}-0.5 \mathrm{Mo}-1.8 \mathrm{~W}$ martensitic heat resistant steel. Mater. Des. 50: 174-180. DOI: doi.org/10.1016/j.matdes.2013.01.072.

3. Sakthivel, T., Laha, K., Parameswaran, P., Panneer Selvi, S., and Chandravathi, K. S. 2015. Effect of thermal aging on microstructure and mechanical properties of P92 steel. Trans. Indian Inst. Met. 68: 411-421. DOI: doi.org/10.1007/s12666-014-0480-x.

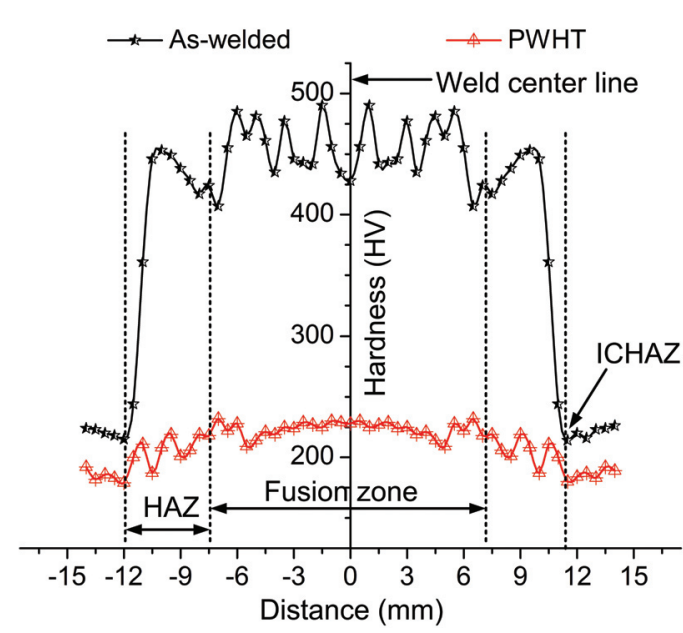

Fig. 8 - Hardness variation across the weldments.

4. Dudko, V., Belyakov, A., and Kaibyshev, R. 2016. Origin of threshold stresses in a P92-type steel. Trans. Indian Inst. Met. 69: 223-227. DOI: doi.org/10.1007/s12666-015-0757-8.

5. Maruyama, K., Sawada, K., and Koike, J. 2001. Strengthening mechanisms of creep resistant tempered martensitic steel. ISIJ Int. 41: 641-653.

6. Barbadikar, D. R., Deshmukh, G. S., Maddi, L., Laha, K., Parameswaran, P., Ballal, A. R., Peshwe, D. R., Paretkar, R. K., Nandagopal, M., and Mathew, M. D. 2015. Effect of normalizing and tempering temperatures on microstructure and mechanical properties of P92 steel. Int. J. Press. Vessel. Pip. 132-133: 97-105. DOI: doi.org/10.1016/j.ijpvp.2015.07.001.

7. Sklenicka, V., Kucharova, K., Svobodová, M., Kvapilová, M., Král, P., and Horváth, L. 2016. Creep properties in similar weld joint of a thick-walled P92 steel pipe. Mater. Charact. 119: 1-12. DOI: doi.org/10.1016/j.matchar.2016.06.033.

8. Saini, N., Pandey, C., Mahapatra, M. M., Narang, H. K., Mulik, R S., and Kumar, P. 2017. A comparative study of ductile-brittle transition behavior and fractography of P91 and P92 steel. Eng. Fail. Anal.: 245-253. DOI: doi.org/10.1016/j.engfailanal.2017.06.044.

9. Saini, N., Pandey, C., and Mahapatra, M. M. 2017. Characterization and evaluation of mechanical properties of CSEF P92 steel for varying normalizing temperature. Mater. Sci. Eng. A 688: 250261. DOI: doi.org/10.1016/j.msea.2017.02.022.

10. Shrestha, T., Alsagabi, S. F., Charit, I., Potirniche, G. P., and Glazoff, M. V. 2015. Effect of heat treatment on microstructure and hardness of Grade 91 Steel. Metals 5: 131-149. DOI: 10.3390/met5010131.

11. Sambamurthy, E., Dutta, S., Panda, A. K., Mitra, A., and Roy, R. K. 2014. Evaluation of post-weld heat treatment behavior in modified $9 \mathrm{Cr}$-1Mo steel weldment by magnetic Barkhausen emission. Int. J. Press. Vessel. Pip. 123-124: 86-91. DOI: doi.org/10.1016/j.ijpvp.2014.08.004.

12. Pandey, C., Giri, A., Mahapatra, M. M., and Kumar, P. 2017. Characterization of microstructure of HAZs in as-welded and service condition of P91 pipe weldments. Met. Mater. Int. 23: 148-162. DOI: doi.org/10.1007/s12540-017-6394-5.

13. Onoro, J. 2006. Weld metal microstructure analysis of 912\% Cr steels. Int. J. Press. Vessel. Pip. 83: 540-545. DOI: doi.org/10.1016/j.ijpvp.2006.03.005.

14. Cai, G., Svensson, L., and Andren, H. 1997. Effect of cooling after welding on microstructure and mechanical properties of 12 Pct Cr steel weld metals. Metall. Mater. Trans. A 28A: 1417-1428. DOI: doi.org/10.1007/s11661-997-0204-5.

15. Abson, D. J., and Rothwell, J. S. 2013. Review of type IV crack- 
ing of weldments in $9-12 \% \mathrm{Cr}$ creep strength enhanced ferritic steels. Int. Mater. Rev. 58: 437-473. DOI: doi.org/10.1179/ $1743280412 Y .0000000016$

16. Mandziej, S. T., Výrostková, A., and Chovet, C. 2011. Microstructure and creep rupture of P92-grade weld metal. Weld. World 55: 37-51. DOI: doi.org/10.1007/BF03321294.

17. Xue, W., Qian-gang, P., Yao-yao, R., Wei, S., Hui-qiang, Z., and Hong, L. 2012. Microstructure and type IV cracking behavior of HAZ in P92 steel weldment. Mater. Sci. Eng. A 552: 493-501. DOI: doi.org/10.1016/j.msea.2012.05.076.

18. Dodo, M. R., Ause, T., Adamu, M. A., and Ibrahim, Y. M. 2016. Effect of post-weld heat treatment on the microstructure and mechanical properties of arc welded medium carbon steel. Niger. J. Technol. 35: 337-343. DOI: http://dx.doi.org/10.4314/njt.v35i2.14.

19. Pandey, C., and Mahapatra, M. M. 2016. Effect of heat treatment on microstructure and hot impact toughness of various zones of P91 welded pipes. J. Mater. Eng. Perform. 25: 2195-2210. DOI: doi.org/10.1007/s11665-016-2064-x.

20. ASTM-E8/E8M. 2017. Standard Test Methods and Definitions for Mechanical Testing of Steel Products, pp. 1-49. DOI: 10.1520/ A0370-17.2.

NITIN SAINI (nit030078@gmail.com), CHANDAN PANDEY, and RAHUL S. MULIK are with the Department of Mechanical and Industrial Engineering, Indian Institute of Technology Roorkee, Uttrakhand, India. MANAS MOHAN MAHAPATRA is with the School of Mechanical Sciences, Indian Institute of Technology, Bhubaneswar, Odisha, India.

\section{Authors: Submit Research Papers Online}

Peer review of research papers is now managed through an online system using Editorial Manager software. Papers can be submitted into the system directly from the Welding Journal page on the AWS website (aws.org) by clicking on "submit papers." You can also access the new site directly at editorialmanager.com/wj/. Follow the instructions to register or log in. This online system streamlines the review process, and makes it easier to submit papers and track their progress. By pub- lishing in the Welding Journal, more than 70,000 members will receive the results of your research.

Additionally, your full paper is posted on the American Welding Society website for FREE access around the globe. There are no page charges, and articles are published in full color. By far, the most people, at the least cost, will recognize your research when you publish in the world-respected Welding Journal.

\section{Welding Journal Now Publishing Direct Object Identifier (DOI) Numbers}

Dear members of the welding research community,

Note that in each issue of the Welding Journal Research Supplement, we are including Direct Object Identifier (DOI) numbers with each of the papers published in print and online. (We have also backnumbered the papers published in the January and February 2018 issues.) A direct object identifier is a unique alphanumeric string assigned by a registration agency (we are using Crossref.org) to identify content and provide a persistent link to its location on the Internet. Our decision to begin assigning a DOI for each paper comes directly from a request by the research community.

As part of our obligation to Crossref.org, we are asked to provide DOI numbers, when available, in the references section of papers. So, if you have submitted a paper to the Welding Journal or are planning on submitting a paper, we ask that you update your references to include DOI numbers whenever possible.

Thank you.

Mary Ruth Johnsen, Publisher, Welding Journal 